\title{
Imaginarios sociales sobre lesbianas en Barranquilla, Colombia
}

\author{
Trabajo de Resultado de Investigación
}

Darling Ayala-Freites ${ }^{14}$

\section{Introducción}

E1 discurso de los derechos humanos y ciudadanía se ha constituido en un componente importante en las democracias en vía de desarrollo. Estos discursos legitiman unos derechos sociales, económicos y políticos, a partir de reformas públicas que deberían beneficiar a todos los grupos sociales. Por tal motivo, al hablar de los derechos humanos en tiempos de crisis social, política, económica y procesos de paz, evidencia la necesidad de que los discursos humanistas tengan en su sustento teórico todos los elementos de la práctica social, entendidos estos como la inclusión de todos los grupos sociales en los diferentes contextos.

En este escenario de problemáticas referidas a las posibilidades reales de los derechos humanos, encontramos el grupo de las mujeres con sus diferencias. Todas tienen en común contextos de dominación sutiles y algunos muy marcados, definidos estos desde las historias personales grupales y de comunidad. ¿Existe ante esto alguna estructura lógica que lo justifique? Desde una postura cultural no se encuentran evidencias históricas contrarias, más bien se constatan y se validan como acciones encaminadas al orden social y cultural de forma legítima.

\footnotetext{
${ }^{14}$ Socióloga, Magíster en Género y Violencia Intrafamiliar. Docente del programa de Sociología, pertenece al Grupo de Investigación "Mujer, Género y Cultura”. Universidad del Atlántico, Barranquilla, Colombia. Contacto: darfrei74@gmail.com
} 
Precisamente, el abordaje humanista a esta lógica, desde una reafirmación de la opresión y de la desigualdad, lo plantean las feministas. Sin embargo, gracias a la asignación de roles, las más afectadas y a la vez reproductora de ellos son las mujeres, que, conjuntamente con los hombres, dan perpetuación a la dominación. Las diferencias no es un asunto que compete a los dos sexos biológicamente aceptados. Esto ha sido, desde la historia de la opresión, una tarea interminable de las mujeres y, sobre todo, el padecerla. La intención de esta investigación es visibilizar la vida de las lesbianas, teniendo en cuenta su visión y la de los otros, para entender la construcción de los imaginarios en Barranquilla.

De este modo se articula la construcción del mundo social, a través de la apreciación tan significativa que permite los imaginarios. Bajo la luz de lo dicho, Fernández (1993) lo define así: "El imaginario social consolida las condiciones reproductivas del poder producido, es decir, garantizan la continuidad del poder producido" (p.240). Con esta frase queda claro que los imaginarios tienen en su fondo histórico e ideológico reproducir percepciones alteradas de lo real, obligando a racionalizar las conductas de las mujeres desde la mirada del patriarcado, que hila fino. El poder y la violencia encierran imágenes donde la atrocidad, a fuerza de ser pensada, necesita problematizar y preguntarse desde sus acciones cómo responder a un modelo social que las imagina y al hacerlo las limita, creando muros alrededor que cierran las posibilidades de individualidad como desarrollo desde su derechos humanos.

Aquí se presentan evidencias empíricas aproximativas, que nos describen los imaginarios sociales de las lesbianas; se hace una descripción de las características sociales de la población encuestada, cómo ellos y ellas ven a las mujeres lesbianas y cómo las identifican y definen.

\section{Imaginarios sociales de las lesbianas en la sociedad}

La lesbianidad está plagada del odio universal que conlleva la idea que las mujeres puedan prescindir de los hombres. "Renunciar a la heterosexualidad es un acto imperdonable"; no desearlos, no existir para la reproducción es motivo suficiente para la discriminación. La sociedad presume de ser incluyente, pero construye un mundo donde las mujeres lesbianas 
no tienen cabida o se les acepta a medias. Desde la mirada de los otros, las lesbianas tienen la etiqueta de perversas, anormales. Ser lesbiana es aún considerado como un estado transitorio, una cuestión de inmadurez en la adolescencia, el deseo de experimentar nuevas cosas que terminarán al llegar a la adultez.

Ahora, si ya están pensadas por los otros desde lo antinatural y patológico, e incluso desde la mirada sexual en la cual son tomados como objetos sexuales, son sujetas de vigilancia de la sociedad heterosexista que estigmatiza lo que es percibido como cuestionable, excesivo o subversivo de los límites sociales. Las sociedades están, en un sentido, menos amenazadas por el hecho de que personas del mismo sexo tengan relaciones sexuales eróticas, que por la capacidad homosexual para reconocer y demostrar la existencia de diferentes estilos de vida, diferentes caminos para librarse una misma de las normas establecidas (Careaga y Cruz, 2004).

Es por ello, que, para la consolidación de esta investigación, se realizó una encuesta que responde en gran medida a la pregunta planteada, respecto a los imaginarios que la sociedad barranquillera ha construido de las mujeres lesbianas. Sin embargo, se encontró que la historia de las mujeres lesbianas han creado espacios desde siempre, obligando a la historia a revisar desde donde han sido miradas. Esto lo constata la revisión del tema; distintas épocas han marcado diferencias. No obstante, a través de la historia encontramos a distintas mujeres que crearon espacios de sociabilidad en los que se debatían sobre la sexualidad, la religión, etc., como lo expone Hunt (s.f):

Mary Daly, una lesbiana que extendió el significado de esta palabra. Ella salió del Placard a comienzo de los años 70, habló, en esa época, públicamente, sobre su identidad sexual, después escribió sobre lo inadecuado de los términos del amor homoerótico definido por el varón; en su léxico imaginativo (Websters' First New Intergalactic Wickedary of the English language, 1987), qué escribió "en confabulación con Jane Caputi", define 'Lesbiana' (siempre con una 'L' mayúscula) como: "Una mujer que ama a una mujer; una mujer que ha roto el terrible tabú contra la mujer que toca a otra mujer, en todos los niveles, rechazando las lealtades falsas a los varones en cada ámbito". Por su parte, Mary Daly rechaza la liberación gay dominada por el varón e insiste en que 
las mujeres sean las protagonistas sin tener en cuenta a sus compañeros sexuales. Rechaza las opciones transgenéricas considerándolas un refuerzo de los roles sexuales estereotipados. Hacen realidad sus compromisos en compañía de amigas mujeres y con la convicción que nuevas maneras de ser son posibles (p.2).

Fueron seleccionadas, de manera aleatoria, 174 personas (97 mujeres y 77 hombres), en edades que oscilan entre los 10 y 75 años, de diferentes profesiones y niveles socioeconómicos, con el fin de establecer e identificar las apreciaciones e imaginarios que se han edificado en torno a las lesbianas en la ciudad de Barranquilla. La importancia de hacer una mirada de las encuestas en las diferentes edades, radica en observar el componente generacional, establecer si, a través del tiempo, han cambiado las apreciaciones en torno a ser lesbiana, resaltando el constructo mental, que permite analizar no solo lo que los otros piensan sino también lo que las lesbianas piensan respecto a ese mundo de ideas que se entreteje sobre ellas.

Al desarrollar todos estos escenarios mentales - en especial la heterosexualidad y la masculinidad como marca que identifica desde el otro la construcción de las lesbianas- es importante reconocer que las apreciaciones sobre la lesbianidad solo están concebidas desde un mundo binario hombre-mujer.

\section{Generalidades sociodemográficas de la población estudiada}

La encuesta fue respondida en su mayoría por mujeres (55,7\%); por su parte, el porcentaje de hombres encuestados fue de 44,3\%. La mayoría de los encuestados está entre los 15 a 20 años, con un 18,3\%, es decir, está en la etapa de la juventud. Según la ley colombiana, a partir del año 2013, basados en la ley estatutaria, bajo el Artículo 5, se reconoce como jóvenes a las personas entre los 14 y los 28 años, los cuales se encuentran en un proceso de consolidación de su autonomía intelectual, pero que fungen como ciudadanos. El 16,6\% corresponde a personas entre 21 y 25 años; seguidamente la población entre 26 y 30 años con $10,9 \%$ y entre 31 y 35 años de edad con 10,3\%. Entre 51 y 55 años con $9,7 \%$.

La encuesta realizada a hombres y mujeres arrojó los siguientes resultados: $13,9 \%$ casado hombre, $13,3 \%$ casada mujer, $27,2 \%$ soltero hombre, 
$37,0 \%$ soltera mujer, $0,6 \%$ separado hombre, $1,2 \%$ separada mujer, $5,8 \%$ unión libre hombres-mujeres, $0,6 \%$ viudos hombres, $0,6 \%$ viudas mujeres. Los resultados de las estadísticas muestran que la soltería es el estado que prima en hombres y mujeres. Esto se debe, en gran medida, a que tanto mujeres como hombres tienen como prioridad prepararse profesionalmente y ser exitosos en sus empleos, sumado al hecho de querer experimentar diferentes relaciones afectivas hasta establecer un compromiso serio, ya sea el matrimonio o decidir vivir en unión libre.

En lo que se refiere al nivel socioeconómico, la mayor parte de la población encuestada pertenece al Nivel 3, con 34,5\%; el 29,8\% pertenece al Nivel 2; el 22,2\% es nivel 1; el 11,7\%, nivel 4; y 1,8\% de los encuestados(as) pertenecen al nivel 5. Estos resultados se pueden explicar porque la mayoría de la población barranquillera pertenece a el nivel medio y acceden sin mayores prejuicios; además están más abiertos a responder conjuntamente. Condiciones como que el tema esté en la prensa y redes sociales permite que haya cierta flexibilidad para participar, aunque esto no implica que tengan ideas respetuosas o de conocimiento sobre el tema. Aquí se refleja el hecho de abrir una encuesta que tuviera en cuenta la participación de jóvenes, incluyendo adolescentes, dada la importancia del tema mirar los niveles sociales permite entender que la participación de todos los niveles socioeconómicos es muy significativo para entender la dinámica del tema en la ciudad.

En cuanto a la educación, que constituye uno de los pilares fundamentales en el desarrollo de los individuos, los resultados que arrojó la encuesta muestran que el nivel educativo de la población encuestada es, en su mayoría, universitarios o con estudios universitarios concluidos $(54,6 \%)$; seguidamente, con estudios secundarios con un $27,6 \%$; técnicos con un $7,5 \%$; tecnológica con $1,7 \%$; y posgrado con $1,7 \%$.

El mayor porcentaje de las personas encuestadas son estudiantes con el 45,5\%. La explicación está en que en la actualidad la sociedad exige jóvenes competentes, preparados, capaces de desarrollar todo tipo de funciones; en estos nuevos tiempos estudiar te garantiza una mejor calidad de vida, además de movilidad social. Encontramos en la encuesta amas de casa, administradores, asesora(es), bacteriólogo(a), estilista, médicos(as) y en general 
una distribución bastante amplia de oficios u ocupaciones que se concentran mayoritariamente en docentes (6.4\%), ingenieros (4.5\%), comerciantes (3.8\%), obreros (2.6\%), abogados (2.6\%) y ninguna o desocupados (3,2\%).

Los resultados arrojaron que el 68,4\% profesa una religión, mientras que el 31,6\% no profesa ninguna relación; la religión católica es la más profesada; entre la población encuestada afirmaron ser católicos con el 67,2\%; esto se explica porque la iglesia católica, desde hace varios siglos, fue declarada como la religión oficial del Estado Colombiano, es la muestra que Colombia sigue siendo un país católico y en gran medida conservador. Sin embargo, también nos muestra que existe una gran diversificación de religiones; al momento de analizar las apreciaciones que se han construido de las lesbianas, el componente religioso, como forma de desacreditar a las mujeres lesbianas, evidencia la influencia Judeo Cristiana, con sus conceptos de las mujeres, en especial lo que debe ser una mujer. Es preocupante que muchas personas afirmaron, "la iglesia dice Dios dice", "Porque estoy fundamentada en mi entorno y en los principios que nos deja Dios"; una lesbofobia sustentada en suposiciones de la verdad absoluta del saber, la otredad no existe como elemento del discurso religioso a menos que sea este un contrario, la severidad de estas violencias han calado de forma continua en el imaginario dejando fuera cualquiera posibilidad de objetar.

Estas frases evidencian que tan lejos puede ser un discurso misógino -Dios hombre perfecto-, todo lo que no se conciba desde esta ideología no tiene cabida; la presunción de verdad absoluta ha sido una constante $y$, de paso, una legitimación tácita de la iglesia, las denominaciones católicas o protestantes no importan. Su sustrato teórico se basa en la opresión de las mujeres, lesbianas y homosexuales; una forma de hacer mella está evidenciado en la figura de la familia como motor de la sociedad, una familia por supuesto conformada por padre madre e hijos, olvidando las diversas familias que componen la realidad de hoy. Comentando al historiador Pablo Rodríguez (1995), si bien es cierto, el lugar preponderante que ocupa la estructura familiar en Colombia, las formas de ser de familia han cambiado de una época a otra; encontramos mujeres que encabezan hogares, viudas, y ello se atribuye en gran medida a la cultura, la etnia, el nivel socioeconómico, porque no podemos pasar por alto que el mismo número de miembros 
que compone una familia pobre, es el de una rica. Si bien el estudio que realiza el historiador abarca el periodo colonial, al analizar la sociedad de hoy es un fenómeno que persiste.

\section{Construcción de imaginarios a partir de los otros y las otras}

Al realizarse la pregunta: ¿Usted conoce lesbianas? El 47.7\% de las mujeres y el $36.9 \%$ de los hombres dijo que sí. Esto se debe en gran medida a que los barranquilleros, a la hora de identificar a una lesbiana, tienen en cuenta la apariencia y en la gran mayoría de las respuestas coinciden en que la expresión corporal, sus rasgos masculinos, el corte de cabello, el modo de andar, hacen fácil percibir si son o no son lesbianas, lo cual nos deja ver que sigue predominando el imaginario de que las lesbianas son netamente masculinas, si bien hay un desconocimiento respecto a la mirada que se ha construido de las lesbianas tipificándolas con el término peyorativo "marimacho", en ese intento del querer ser hombre y no poder. La encuesta muestra que la lesbianidad en la sociedad actual es un tema visible, pero, que aún genera estupor cuando se habla de él. Platero (2009) afirma:

Podríamos decir que la lesbiana es una sujeta mestiza que rompe la lógica binaria, una persona incomoda que no existe identitariamente, y que, sin embargo, tiene capacidad para generar formas creativas de resistencia y señalar las exclusiones sociales de las que es objeto (p.42).

De alguna manera, este imaginario de que las lesbianas son masculinas dejan por fuera mujeres femeninas lesbianas, e incluso se corre el riesgo de equivocarse: todas las mujeres de apariencia masculina algunas no son lesbianas, es esta una de las razones que hace difícil medir la invisibilización de las lesbianas. En este punto es evidente la percepción del imaginario:

El carácter principal de una mujer invertida sexualmente es un cierto grado de masculinidad, los movimientos bruscos y enérgicos, la actitud y el andar, la mirada directa, las inflexiones de voz, sobre todo, la manera de estar con un hombre, sin timidez ni audacia (Falquet, 2004, p.36).

Por otro lado, el 7.4\% de hombres y el $8 \%$ de las mujeres encuestadas, que dijo no conocer lesbianas, demuestra que es difícil percibir aun en estos días a las mujeres lesbianas, y esto se debe en gran medida a que las relacio- 
nes entre mujeres son mucho más íntimas que entre los hombres; la prueba está en que dos mujeres pueden ir tranquilamente agarradas de la mano y no es visto como algo impropio, por el contrario, en los hombres es motivo de escándalo.

Al formular la pregunta ¿Tienes amigas, conocidas, familiares, compañeras de trabajo o estudios lesbianas?, los porcentajes fueron los siguientes: el 35,4\% de los hombres y el $47.4 \%$ de las mujeres dio una respuesta afirmativa. Mientras que el $9.1 \%$ y el $8 \%$ de hombres y mujeres, respectivamente, respondió que no. Es claro que el resultado que obtuvo un mayor porcentaje, muestra que conoce a las lesbianas en los diferentes escenarios en los que ellas se desenvuelven, como el trabajo, la casa, el barrio, la familia, y lugares públicos, sumado eso la apariencia, las expresiones corporales, el voz a voz juega un papel determinante para definir qué mujer es lesbiana y quién no lo es. Se puede inferir, también, que si las mujeres no tienen ademanes masculinos, o no tienen un carácter fuerte se hace difícil concluir cuál es su sexualidad y esto en cierta manera es una de las formas de invisibilizar a las mujeres lesbianas femeninas, como lo he venido afirmando a lo largo de esta investigación en las apreciaciones de los encuestados.

Las lesbianas analizadas desde la otredad, son vistas como un grupo aparte que no logra articularse con los demás miembros de la sociedad, no hacen parte del todo que configura el universo. En la encuesta, al preguntarle a los hombres si tienen amigas, conocidas, familiares, compañeras de trabajo o estudio que sean lesbianas, el porcentaje más alto fue el de conocidas con un 29,5\%; con lo cual se puede inferir que los encuestados piensan que establecer relaciones interpersonales con las lesbianas es algo difícil y se soporta cuando esbozan argumentos como: "Son rudas, no trato con mujeres asì " o "son peligrosas y resentidas", encontramos frases con un contenido fuerte como esta "Me dan asco, no quisiera conocer a ninguna". Lo anterior nos deja entrever, que prefieren tener un trato distante con las mujeres lesbianas, como si ser lesbiana fuera una enfermedad contagiosa. Por su parte, el 17,8\% dijo tener una relación de amistad; el 13\% compañeras de estudio el 11.6\% compañeras de trabajo. Las mujeres por su parte al responder el tipo de relación que tienen con las mujeres lesbianas respondieron de manera similar a los hombres: el $36.3 \%$ son conocidas, le sigue $28.1 \%$ amigas el $13.7 \%$ compañeras de estudio y el $6.2 \%$ compañeras de trabajo. 
Los datos muestran que la variable que obtuvo la menor frecuencia es la de familiares, con el $0.7 \%$ para mujeres y hombres, esto se puede explicar en gran medida porque la familia, puede llegar a ser su principal "juez”; en el núcleo familiar resulta un problema aceptar algo que es considerado como anormal, "un peligro que no se advierte". Por otro lado, la familia puede aceptar que su hermana, hija, tía, sobrina, prima, sea lesbiana, pero es una aceptación a medias, temas como su relación afectiva no se tocan en casa.

\section{Cómo identifica a una mujer lesbiana}

Tabla 1. ¿Cómo identifica a una mujer lesbiana?

\begin{tabular}{|l|c|c|}
\hline \multicolumn{1}{|c|}{ ¿Cómo identifica a una mujer lesbiana? } & Masculino & Femenino \\
\hline Ropa & $4,1 \%$ & $5,8 \%$ \\
\hline Forma de comportarse & $7,6 \%$ & $24,4 \%$ \\
\hline Corte de cabello & $1,2 \%$ & $0,0 \%$ \\
\hline Ropa, Forma de comportarse, Corte de cabello & $11,6 \%$ & $14,5 \%$ \\
\hline Ropa, Forma de comportarse & $8,1 \%$ & $5,8 \%$ \\
\hline Ropa, Corte de cabello & $1,2 \%$ & $0,0 \%$ \\
\hline Forma de comportarse, corte de cabello & $1,7 \%$ & $0,0 \%$ \\
\hline
\end{tabular}

Fuente: Elaboración propia.

Al realizar la pregunta ¿Cómo identifica a una lesbiana? las respuestas estuvieron relacionadas con la apariencia de las mujeres como la forma de comportarse; en general las identifica asociando tres características externas (ropa, forma de comportarse, corte de cabello). En consecuencia, es evidente que estas apreciaciones están relacionadas con la particularidad de mujeres lesbianas que desarrollan rasgos masculinos; la identificación parte precisamente de las similitudes que identifican con los hombres. Esto connota un imaginario relacionada con la masculinidad, entendida esta como un hecho solamente permitido a los hombres; la forma de comportarse es, asimismo, una conducta que identifican hombres y mujeres como la forma de identificar a las lesbianas. Estas posiciones, desde las observaciones de encuestados, no son novedosas, mantienen la estructura de roles como una identificación caricaturesca de la lesbianidad. 
Sin embargo, los hombres con respecto a las mujeres en la encuesta asumieron mucha más participación no solo para identificarlas si no que también sus apreciaciones marcadas relacionaron la lesbianidad con la de alguna forma asumen una copia de ser hombre, por ello, surge un nuevo interrogante ¿Cómo se comportan las lesbianas? Al consultarse respondieron que las lesbianas tienden a ser bruscas, poco femeninas, celosas, posesivas, es decir se repite el modelo heterosexual en el cual uno ejerce el papel de dominador y el otro de dominado; en las respuestas encontramos la necesidad de ver en las relaciones lésbicas una relación heterosexual, a lo que Dolores Juliano afirma:

Establecer relaciones sin un modelo en la cual no hay roles tiene sus inconvenientes, porque si bien es cierto que permite la innovación deja confusa las expectativas de lo que se espera de cada parte, por lo general en las relaciones heterosexuales se da un rol de superioridad por parte del hombre y otro de tolerancia y resignación por parte de la mujer, debido a que depende económicamente de este, si no existiera superioridad ni dependencia económica no queda más remedio que desarrollar una relación madura pactada desde la libertad y el respeto mutuo (21de diciembre de 2005).

No obstante, la heterosexualidad es el único modelo que las mujeres lesbianas conocen, por eso tienden a repetirlos. Es por ello, que no es de extrañar que a las lesbianas casi siempre les pregunten ¿Cuál es el hombre?

\section{Denominaciones de ser lesbianas desde los otros y otras}

Desde la mirada de los otros y las otras, múltiples son las denominaciones que ha construido la sociedad barranquillera respecto al "ser lesbiana”, de su conducta sexual, de su accionar como personas. Son mujeres no deseadas, no respetadas, e incluso subvaloradas. A continuación, algunas denominaciones reflejadas en las encuestas, entrevistas y focales que se realizaron para fundamentar la apuesta investigativa.

\section{Cauchera, picha con raja}

Se refiere a un falo de mentiras, una idea errada del sexo, que solo es satisfactorio con la penetración o solo es posible entre heterosexuales. 
La simplicidad de estos supuestos ubica a las lesbianas en un sitio de exclusión y marginación, vulnerando sus derechos humanos.

\section{Antinatural, loca}

Se encuentra amparada en el imaginario de la locura y el desajuste emocional, manifestando que la sexualidad solo está normalizada desde el deseo heterosexual. Así lo reafirma Gimeno (2003):

Durante el siglo XIX y hasta la segunda mitad del siglo XX se abre paso al modelo patológico de la lesbiana. No es necesario explicar cómo los diagnósticos psiquiátricos y psicológicos han sido empleados como herramientas de opresión y control de los grupos que amenazan la cultura dominante, entre ellos, las mujeres, no solo las lesbianas. Sabemos cómo las mujeres que desafían el modelo femenino han sido o bien invisibilizadas, o bien estigmatizadas con diagnóstico de enfermedades no solo psiquiátricas y sabemos cómo la etiqueta de enferma mental ha servido para despolitizar incipientes movimientos de disconformidad con la realidad dominante (s.p.).

La etiqueta de loca es una de las maneras de justificar, neutralizar y deslegitimizar la práctica lésbica. De las mujeres se espera que ocupen su rol asignado en la sociedad, salirse de este molde implica un problema, porque se evidencia que existen otras formas de ser.

\section{Las extrañas}

Imaginario invasivo y violento que históricamente ha sido el resultado de la mirada patológica sobre la lesbianidad: las lesbianas desafían el orden heterosexual y al hacerlo subvierten la primera regla del patriarcado que es la exclusividad sexual para los hombres. A diferencia de los gais que mantienen su status de hombre y sus beneficios, las lesbianas carecen de eso. Por tal motivo, su inversión las sitúa en lo raro, provocando las miradas acusadoras, los comentarios y la violencia simbólica en respuesta a la afrenta. Ser y sentir, orientar lo erótico, amoroso y sexual hacia el mismo sexo en una cultura donde la heterosexualidad es obligatoria. "No se trata de sustituir unos términos por otros. No se trata tampoco de deshacerse de las marcas de género o de las referencias a las heterosexualidades, sino de modificar las posiciones de enunciación” (Preciado, 2002, p. 23). 


\section{La mirada masculina del deseo}

Desde el patriarcado, el sexo está organizado en la estructura cultural, considerando el deseo como apropiación de los hombres. Sin embargo, las lesbianas escapan a su deseo en la práctica objetiva, pero en el ámbito de poder, el cuerpo se hace objeto: la invención de la pornografía con lesbianas.

\section{Coquetas}

Aquí sobresale la hipersenxualidad, se les considera mujeres promiscuas y provocadoras en afirmaciones como "mujeres vulgares que no respetan su cuerpo" o son "ninfómanas". Aseveraciones de este tipo tienen la creencia fundamentada del arquetipo mariano ${ }^{15}$ : una mujer dulce y pueril. Según los imaginarios encontrados en las encuestas, las mujeres lesbianas rompen con este ideal, considerándose que las relaciones entre mujeres es una profanación a sus cuerpos.

\section{No han probado hombre}

Expresión muy interiorizada, proveniente del imaginario heterosexual. No se concibe las mujeres sin los hombres mucho menos desde lo sexual, una apreciación cargada de prejuicio donde lo patológico se asoma de forma totalizadora. El trauma está ahí, "como no han tenido sexo con hombres entonces no sabe lo que se pierden”. Existe una frase referida a las lesbianas que nunca se acuestan con hombres, las llaman "lesbianas de oro". Tal vez categorizar la esencia femenina desde el cuerpo y su supuesta complementariedad es un discurso que deviene de esa analogía si no tienes sexo con hombre te pierdes de algo o te falta algo. Lo patológico se asoma determinando no el sentir sino la forma, no importa la elección, implica la trasgresión de la norma convertida en castigo.

\section{Problemática, loca}

La categoría de loca es reiterativa en las respuestas de los y las encuestadas, la idea de que son mujeres excesivamente celosas que no se permiten

${ }^{15}$ Es un concepto sociológico simétrico al del machismo, dentro de la interpretación feminista del patriarcado, según la cual la imagen idealizada de la mujer es un arquetipo o estereotipo (estereotipo social, como el que la religión cristiana realiza en el "espejo y paradigma mariano"). 
ser felices porque manejan una presión constante sobre sus parejas que las imposibilita vivir tranquilas está arraigada. Frente a lo anterior, estas fueron algunas de las apreciaciones de los encuestados, esta apreciación es constatada en relaciones heterosexuales de igual forma.

\section{Tijeras}

Denota la práctica sexual común entre lesbianas. Las expresiones que configuran la anormalidad están presentes, como también las palabras usuales: camioneras, areperas, marimachos y lenchas, todas situadas en la representación de lo grotesco. La descalificación inmersa en estos apelativos puede ser una estrategia de desaprobación que pone a todas las lesbianas en el mismo lugar. Aunque ellas no se reconocen como tales, la gente del común sigue creyendo que así es, que son anormales y enfermas, un discurso que ha predominado y calado en el imaginario colectivo.

Aunque las definiciones no son abundantes, es cierto que tiene un componente doblemente discriminador por ser mujeres y lesbianas, sin contar con aspectos como la etnia y la raza. En este sentido, las posibilidades de marginación se acentúan. Por eso al definir lesbianas, las acepciones son limitadas. El hecho histórico confirma que si es posible una plenitud de la vida desde la elección de la lesbianidad lo único visible será la lesbofobia y, con ello, la invisibilización del hecho lesbiano.

Un imaginario sobre las mujeres lesbianas en la sociedad barranquillera está relacionado con lo religioso, la fe, identificando que están alejadas de Dios, que están en mal camino, pecadoras y malas por su condición. Otra de los imaginarios tiene lugar en la presunción de acciones masculinas, mandonas, dominantes, poco femeninas, antinaturales: "es feo no las tolero", "tienen hábitos de hombres", "apáticas a los hombres".

Por último, el componente psicológico como elemento desencadenante de la acción lesbiana, donde predomina: peligrosa, resentidas locas, enfermas. Concretamente los imaginaros están relacionados con imágenes que han permanecido históricamente en el tiempo, por lo que las recurrencias y analogías hechas por los encuestados no se alejan de los conceptos que constantemente se han asociado al ser lesbiana. Esto indica que el desconocimiento acerca de la lesbianidad es uno de los elementos fundamentales 
para la proliferación del odio hacia ellas. Cuando se desconoce una realidad es fácil tergiversarla, así los conceptos negativos pueden calar de forma fácil en la construcción de la realidad.

Las mujeres comparten la desigualdad e inequidad. El respeto de los derechos de la población femenina encierra, desde la "normalidad", demasiadas renuncias, aunque se han cambiado las realidades sociales e históricas, no es suficiente.

La resignación e invisibilización por parte de los espectadores del mundo ajeno, es palpable cuando perciben en la lesbianidad lo amorfo, cimentado en la negación del hecho lesbiano. No verlo es quizá provocado por la forma en que muchas lesbianas se esconden, muchas se ocultan repetidamente, logrando que lo no dicho se convierta en desconocimiento, plasmando una vez más esa imagen en el colectivo de no nombrarlas. Foucault (1977) lo nombra: "Todo conocimiento, una vez aplicado en el mundo real, tiene efectos reales, y en ese sentido al menos, 'se vuelve verdadero"' (p.26). Entonces, las prácticas que hegemonizan lo sexual han pervivido como memoria de lo que se debe obedecer. Quizá por eso Foucault, es quien mejor lo amplía en la repetición constante del mundo social más que imaginado e idealizado. La institucionalización de las prácticas sexuales que también son hegemónicas desde la otra realidad no nombrada.

\section{El porqué de las apreciaciones}

- "Porque tengo creencias fieles a la palabra de Dios. Siempre ha sido hombre-mujer".

- "Porque Dios le dio un órgano para procrear, no para que se gusten entre ellas".

- "Porque creci en un hogar conservador y mi familia y valores no me permiten congeniar con ese tipo de personas".

- "Dios no creo mujeres lesbianas".

- "Porque en la Biblia dice que los gais no entran al reino de Dios". 
Las anteriores apreciaciones fueron tomadas de las personas encuestadas y observamos que hay una extendida creencia que las lesbianas son un sujeto monstruoso, deforme e incompleto cada imaginario encuentra cabida en la falta de algo, en la siquis dañada y una moral contranatural. Por lo tanto, el sujeto lesbiano se ha construido invisible, esta permanencia en el tiempo ha fundamentado lo no nombrado, lo oculto que permite construir y sostener ideas erradas de la lesbianidad.

Esta invisibilidad en la historia (una invisibilidad que, cabe insistir, solo depende de los términos en que hablamos de deseo) se traduce en una invisibilidad en literatura y posteriormente en las creaciones de arte popular, incluyendo el cine y la televisión. Esto no significa que no existan corrientes homoeróticas en las relaciones entre mujeres en los textos, todo lo contrario, simplemente que el heterosexismo se resiste a calificarlas de lésbicas excepto en condiciones muy específicas y especialmente cuando tal etiqueta resta poder a las implicadas y tiñe de negatividad la representación (Mira, Suárez y Méndez, 2010, p. 7).

En conclusión, la mirada de los otros emerge de un profundo desconocimiento y miedo. Las percepciones negativas son ampliamente lesbofobicas, deformando la realidad de las mujeres lesbianas. Ahora bien, la forma en que niegan a las lesbianas, está relacionada con lo religioso de lo impuro y demoníaco, la explicación obedece a la ideología religiosa que influye en la mente de sus feligreses, generado un odio acérrimo a las diferencias.

Los cambios culturales son lentos, alimentan la lista interminable de adjetivos desdeñosos que generación tras generación han desvirtuado el imaginario lésbico de lo amorfo, pero en forma constante se trasforma manteniéndose incólume ante la cultura.

\section{Lesbianas y derechos humanos}

Desde la mirada del derecho es notable que hombres y mujeres no son iguales, las mujeres tienen aspectos culturales marcados que la han colocado en un grupo vulnerable, a partir de cómo son pensadas y vistas. Las investigaciones en el tema han identificado no solo la consolidación del poder en algo sutil y no pensable, esta diatriba deriva en comportamientos asociados a la cultura y lo que se espera de cada cual en esta configuración. 
Dadas las particularidades de cada época, algo se ha mantenido intacto, es precisamente la agudización de los problemas de las mujeres, estos han tenido unas particularidades en el tiempo, es la perpetuación de la marginalización.

Precisamente, para esta construcción de problemas, es notable que hayan sido más llevaderos desde la democracia, que desde otros regímenes políticos. Este es quizá uno de los aportes más significativos de la democracia, ya que logra la consolidación de procesos de incidencia para la reivindicación de problemas específicos para grupos específicos en la sociedad, que han servido para una descripción del problema, siendo el primer paso para la visibilizacion del tema en un contexto social determinado, sea este dictatorial o democrático. "Los nuevos marcos interpretativos que postulan la existencia de un sistema injusto de relaciones sociales genéricas permiten a las mujeres reinterpretar sus experiencias dentro de un nuevo sistema de desigualdad y comprometerse con el cambio de estas injustas relaciones" (Araujo, 2000, p.137).

El compromiso con estos temas no es fácil, porque los problemas de las mujeres tienen atenuantes de injusticia y negligencia; temas tan específicos como el feminicidio, por ejemplo, representa el punto máximo de la violencia. Por consiguiente, es importante decir que fenómenos como la violación es uno de los temas más álgidos en la escena jurídica, ya que posee elementos muy particulares que tienen que ver con una construcción del cuerpo de las mujeres como algo maleable no visto desde el sentido estricto de lo humano; la agresión representa la invisibilización del repudio, en términos más concretos la misoginia, los casos de feminicidio sexual, son los que mejor describen estos hechos brutales.

La impunidad en los casos de feminicidio en la ciudad de Juárez, los miles de víctimas del conflicto armado internos en países de América latina como Perú, bajo el mando de Fujimori, en Chile con Pinochet y por supuesto en Colombia. Paradójicamente, en pleno siglo XX aun encontramos similitudes con estas acciones bárbaras. Así lo describe el periodista López de Miguel (2014), donde nuevamente se constata que los cuerpos no tienen nombre, ni nacionalidad, en Sudáfrica uno de los países más avanzados en políticas que favorecen a la comunidad LGBTI, se práctica la "violación 
correctiva”, ejercidas sobre mujeres lesbianas y bisexuales; comenta además que en 2009, según cifras de la organización Action Aid'16 se registraron 500.000 casos.

Al hablar de la perspectiva de género, se encuentran diferentes acepciones que tienen en su hacer histórico unas razones propias, que obedecen al quehacer de su época y contexto social, suele ser esto, de alguna manera, lo más problemático de estudiar. La categoría género, quizá, quien mejor puede contextualizar su incursión en los análisis de los humanistas es Joan W. Scott (1986); sus estudios posibilitan comprender los problemas que ha enfrentado para permanecer en el escenario de las ciencias sociales.

La poca comprensión en su aplicación podría ser uno de los problemas más apremiantes, ya que para algunos es un tema que trata solo la historia de la naturalización de la opresión hacia las mujeres, siendo la categoría de género una gran posibilidad de pensar las subjetividades. Ahora, dentro de las subjetividades, la democracia como escenario ideal se vuelve resbaloso para grupos marginados estigmatizados y subvalorados, dentro de todas estas apreciaciones hay algo más; esto tiene que ver con la aplicación del derecho. La legislación colombiana tiene un bloque constitucional muy completo respecto a este tema, por ejemplo la Ley 1257 de 2008. Sin embargo, es inoperante; en este orden de ideas es pertinente preguntar $¿$ Cuáles son los grupos más afectados por la mala práctica del derecho? ¿De qué forma pueden acceder todas las personas, si es un derecho para todos? Muchos interrogantes se arrojan sobre la palestra, pero, nada está más lejos de acceder realmente a los derechos humanos.

Dentro de estas dificultades para evidenciar injusticias y sobre todo para visibilizar problemas, la interseccionalidad nos permite ahondar en las especificidades de cada grupo marginado.

La transversalidad es una teoría feminista, una metodología para la investigación y una herramienta para la justicia de género y la justicia económica ámbito de la justicia social. Comienza con la premisa de

\footnotetext{
${ }^{16}$ ActionAid International es una organización de desarrollo internacional con sede en el Reino Unido. Desde su fundación en 1972, ha trabajado por atenuar la pobreza de niños, familias y comunidades de más de 30 países de África, Asia, Latinoamérica y el Caribe.
} 
que la gente vive identidades múltiples, formadas por varias capas, que se derivan de las relaciones sociales, la historia y la operación de las estructuras (Instituto Nacional de Mujeres, 2004, p.1).

La pregunta ahora sería ¿por qué utilizar esta metodología? Dadas las complejidades de las mujeres, es importante entender las diferencias dentro del mismo grupo que no es homogéneo y que tiene unas particularidades históricas y sociales importantes en la construcción de teorías que abarquen la especificidad de la violencia por grupos poblacionales desde la raza, etnia e inclinación sexual, así como se documenta en la revista número 9 de Derechos de las mujeres y cambio económico (Instituto Nacional de Mujeres, 2004).

Como consecuencia de sus múltiples identidades, algunas mujeres se ven empujadas a los márgenes y experimentan profundas discriminaciones, mientras que otras se benefician de posiciones más privilegiadas. El análisis interseccional nos ayuda a visualizar cómo convergen distintos tipos de discriminación: en términos de intersección o de superposición de identidades. Más aún, nos ayuda a entender y a establecer el impacto de dicha convergencia en situaciones de oportunidades y acceso a derechos, y a ver cómo las políticas, los programas, los servicios y las leyes que inciden sobre un aspecto de nuestras vidas están inexorablemente vinculadas a los demás.

Otros aspectos son relevantes en el análisis de como evidenciar problemáticas que afectan específicamente a grupos sociales, se podría decir, que existe una necesidad de escudriñar las diferencias no solo como efecto de un trabajo desde los derechos humanos de las personas, sino más bien desde la teorización misma del problema para tener una base de conceptos que integren efectivamente la amplitud de variables que a simple vista no están, ya que están inmersas en una dominación que las hace invisibles, cada análisis no solo particulariza, sino que profundiza el conocimiento de tal forma que sostiene un hilo de análisis comprensible desde la teoría sociológica.

La propia construcción social que la caracteriza institucionalmente de una forma de desventaja social: la asimetría entre hombres y mujeres evidencia desventajas sociales, específicamente la económica, ya que no solo 
segrega si no que se convierte en una constante reafirmación de la violación de los derechos de las personas, haciéndose una carga que tiene por supuesto unas marcas ideológicas que reafirman la marginación, esta complejidad obliga de forma constante a una automarginación, no solo subvaloriza la esencia humana, sino que también genera un dilema de tipo ontológico en los individuos, esta constante fundamenta teorías inmersas no solo en la sociología si no en la psicología, haciendo de este modo que la integralidad de los problemas sean analizados desde una interdisciplinariedad efectiva y lo suficientemente argumentada.

Entender la construcción de lo biológico a partir de la cultura supone uno de los retos más acuciantes, es decir en la ¿̇redefinición de roles, cabe acaso una posible deconstrucción de los mismos? Esta pregunta obliga a ver el tema de la perspectiva desde todas las miradas para comprender las situaciones particulares y especiales de los grupos poblacionales.

La situación actual de los Derechos Humanos de las personas LGBTI es preocupante; cada una de las personas que conforma el colectivo LGBTI tiene una forma de afectación diferente en sus derechos fundamentales, teórica y políticamente comparten algunas preocupaciones comunes que se derivan del derecho a la libertad de orientación sexual. Las violaciones a los Derechos Humanos de las personas LGBTI no son comparables ni en magnitud, ni en características de las mismas, a las violaciones a cada una de las partes que componen este colectivo. Las organizaciones no gubernamentales, algunos de los órganos de control de los Derechos Humanos y el movimiento lésbico feminista internacional han marcado un camino hacia el reconocimiento de la identidad lesbiana y hacia el respeto de los Derechos Humanos de estas mujeres, con importantes logros tanto en la esfera social y política como jurídica. La Corte resolvió a su favor, creando un precedente fundamental que abrió la puerta para que otras personas gais o lesbianas hagan valer su derecho a la libertad y a la autodeterminación sexual.

Es de vital importancia mencionar los logros que han alcanzado aquellos a quienes llamamos diversos y de los cuales las lesbianas hacen parte.

"Los diversos" encarnan las anormalidades del sistema, son los subordinados, quienes personifican la alteridad, la diferencia... en fin los 
abyectos. Justamente así son representados por la prensa, como "los otros," ese grupo distinto, siempre designados como ellos: los que no hacen parte de" nosotros," los diferentes a la mayoría social. Para ésos nos fueron escritas las leyes, por tanto, es necesario en pro de la igualdad pretendida por el estado moderno, teorizarlos de tal manera que siga siendo los "otros"-necesarios para que exista lo UNO-, y aun así puedan acceder a "los derechos universales", eso sí en necesidad de cambiar o trasgredir el paradigma, sin menester de historizar la marca ni mostrar sus relaciones de poder, pues ello, implicaría dar claridad sobre cómo funcionan los poderes ejercidos desde las elites masculinas, heterosexuales y blancas (Rivera Tirado, 2013, p.117).

Acceder a los "Derechos Universales" no ha sido una tarea fácil, el recorrido se ha tornado largo y tormentoso en el cual no se está exento de críticas y señalamientos por ser la excepción a la regla, es por ello, que considero importante, esbozar algunos de los logros que ha alcanzado la población diversa en Colombia, pArtiendo de la constitución de 1991, hoy vigente, la Constitución estipula que Colombia, es un país multiétnico y pluricultural, en cual prevalece el derecho a la igualdad, y al libre desarrollo de la identidad.

Bajo esta premisa la población diversa ha luchado por alcanzar distintos reconocimientos en pro de sus derechos como ciudadanos y ciudadanas; en el año 2000 el Congreso de la República colombiana, establece en el Código Penal, que el delito merece una plena mayor si se concluye que el motivo de la agresión obedece a la orientación sexual, la Corte Constitucional, por su parte, ha cumplido un papel importante en la defensa de los derechos de la población LGBT. No obstante, mencionaremos los logros en asuntos de leyes que amparan a las lesbianas: En 1998 se declara inconstitucional una medida que sancionaba a profesores gays o lesbianas por su orientación sexual; en 2000 las personas con diversidad sexual pueden expresar de manera publica su orientación; en 2002 se estableció que los colegios no cuentan con la potestad para crear manuales de convivencia que sancionen al lesbianismo o la homosexualidad; en 2007 se acepta la unión entre parejas del mismo sexo, en el cual ambos tienen derechos patrimoniales; en 2008 se permite la pensión y obligación alimentaria a parejas del mismo sexo. 
En la Corte Constitucional les reconoció a las parejas del mismo sexo el derecho a formar un patrimonio conjunto y afiliar a la pareja a la seguridad social en salud mediante la Sentencia C-075/07 y C811/07 (Restrepo-Pimienta y Molina-Imitola, 2014). El fallo de derechos patrimoniales fue el resultado de una demanda de inconstitucionalidad a la Ley 54 de 1990, interpuesta por Colombia Diversa y por docentes profesionales del Grupo de Derecho de Interés Público de la Universidad de los Andes. El fallo de seguridad social fue el resultado de una demanda de inconstitucionalidad a la Ley 1001992 interpuesta por un estudiante de la ciudad de Tunja y presentada en la Corte una vez se dictó el fallo de derecho patrimonial (Colombia Diversa, 2017).

Sumado a lo anterior, se creó un proyecto de ley antidiscriminación consagrado en el Artículo 13 de la Constitución Política, con la finalidad de advertir cualquier tipo de discriminación que se practique en contra de un ciudadano colombiano, así como fomentar la igualdad entre todos; frente a esto la directora de Colombia Diversa, Marcela Sánchez Buitrago, ha manifestado que esta ley de antidiscriminación es una oportunidad de construir una apuesta común por la igualdad entre diferentes poblaciones discriminadas: afrodescendientes, negros, indígenas, mujeres, personas con discapacidad, gays y lesbianas.

E1 28 de enero del 2009, la Corte Constitucional de Colombia, por medio de la Sentencia, C-029, reconoció a las parejas del mismo sexo una serie de derechos civiles, políticos, sociales, económicos, migratorios y penales que hasta el momento solo eran reconocidos para las uniones de hecho homosexuales. El fallo fue el resultado de una demanda que presentaron, el 28 de abril de 2008, Colombia Diversa, el Centro de Estudios Derecho, Justicia y Sociedad (Dejusticia) y el Grupo de Derecho de Interés Público de la Universidad de los Andes sobre la igualdad de derechos de las parejas heterosexuales y del mismo sexo en unión marital de hecho (Colombia Diversa, 2009).

Por otro lado, en el contexto latinoamericano, los países han realizado una lucha en conjunto por la defensa de la población diversa. El 26 de septiembre del 2014, tuvo lugar en Ginebra la presentación de la resolución ante el Consejo de Derechos Humanos de Naciones Unidas, por parte de 
países latinoamericanos, la resolución presentada busca combatir la violencia y discriminación por la orientación sexual e identidad de género, dicha resolución sigue la labor que se venía gestando con la aprobación de la Resolución de junio del 2011, la cual fue la primera en defender los derechos humanos de las personas con orientación sexual distinta a la heterosexual, pues bien, la resolución que presentaron los países latinoamericanos fue aceptada llegándose al acuerdo de actualizar un estudio del año 2012, en el que se observe los índices de violencia y discriminación por motivos de orientación sexual, además, los asistentes a este evento sentaron su posición entorno a la problemática y aplaudieron la labor de los países latinoamericanos.

"Nunca hay una justificación para la degradación, el envilecimiento o la explotación de otros seres humanos, cualquiera que sea el motivo: la nacionalidad, la raza, la etnia, la religión, el género, la orientación sexual, la discapacidad, la edad o la casta", dijo Al Hussein. Estos comentarios siguen el trabajo innovador de su predecesor, Navi Pillay, y del secretario general de la ONU, Ban KI-Moon, en cuestiones de orientación sexual e identidad de género (Human Rights Watch 2014, párr. 8).

En el panel realizado por el Consejo Económico y Social de las $\mathrm{Na}$ ciones Unidas (ECOSOC), el cual tuvo lugar en Ginebra en el año 2001, se traza como principal eje que se apliquen los compromisos establecidos con respecto a la igualdad de género y el empoderamiento de la mujer, se hizo un llamado a repensar los estereotipos que impiden que se adelanten progresos en la lucha por la igualdad de género es una cárcel que mantiene cautivo a hombres y mujeres en los roles que culturalmente y socialmente les han asignado, evitando de esta forma que se dé una verdadera igualdad, es por ello necesario la creación de nuevas políticas que contrarresten esa estructura mental.

Es evidente que mientras se tenga una mirada sesgada y heteronormatizada, no se podrá lograr que los avances jurídicos tengan la injerencia necesaria para lograr derribar los prejuicios que contribuyen a que persistan percepciones negativas sobre población LGBTI y sobre las mujeres lesbianas en específico. Mientras esto siga siendo la bandera de pocas, no se lograra de forma acelerada cambiar los imaginarios sobre la diversidad 
sexual. Como lo explica Pisano, la cultura lésbica, está fundamentada fuertemente en la heterosexualidad porque aún no ha podido liberarse del lastre del patriarcado y esto no ha sido posible porque persiste la fuerza de la costumbre, como diría Margarita Pisano (1999): "No hay otra forma de ser", además deben de reproducir el modelo de familia heterosexual.

\section{Conclusiones}

Esta investigación permitió identificar los imaginarios que la sociedad barranquillera ha construido de lo que es ser lesbiana, encontramos que estas apreciaciones son ratificadas por las lesbianas lo cual quiere decir que las lesbianas en Barranquilla no tienen imaginarios con respecto a su propio mundo, ellas de alguna manera constatan lo que los otros miran. Por otro lado, enfatizan en que ser lesbiana no es algo homogéneo que existen diversos tipos de lesbianas, se vuelve una constante relacionar a las lesbianas con el querer ser hombres y no poder, además de asumir que todas son masculinas. Además de las lesbianas femeninas, haciendo hincapié en la lesbiana masculina como machorra y otorgándole a la segunda un rol de bisexualidad posible.

Podemos decir, que las construcciones sociales y de genero afectan de manera diferentes a las mujeres; además de esto los prejuicios, estigmas y estereotipos han fraccionado a la sociedad, aportando desigualdades preocupantes en el desarrollo de la vida productiva de las mujeres lesbianas. Sin embargo, aunque hay avances importantes en materia jurídica, no se reflejan, lo que permite inferir la pertinencia de las categorías de análisis desde una perspectiva de género que aporte miradas diferentes, fundamentadas de los grupos marginalizados.

Deconstruir es la tarea más difícil, cambiar los esquemas mentales e ingresar otros que generan en el individuo grandes dificultades de asimilación, no se pude olvidar que la dominación masculina afecta a las mujeres de forma particular, pero se extiende también en todos los hombres, posibilitando un gran reto, destruir y construir, fomentar y trabajar por la validación de los derechos humanos de todos y todas.

La repetición de roles heterosexuales como lugar asignado para la realización de su vidas y la violencia de los imaginarios han calado en ellas 
logrando desconfigurar la realidad, generando de este modo, en el grupo poblacional estudiado, esferas masculinas para todos sus actos; duras denominaciones que ellas reconocen como una constante que las obliga a no pensar ni asumirse. Ellas identifican los imaginarios desde la mirada de los otros, su apreciación de esto se evidencia en las denominaciones reconocidas como imaginarios que le han conferido la invisibilización, con esto se piensan desde los estereotipos introyectadas como formas de relacionarse en la sociedad.

En la evidencia empírica analizada, ellas expresan desde la simpleza hasta la indignación, el lugar de ellas en la cosmovisión imaginaria de la sociedad, donde, los otros son los protagonistas. Estos asumen con vehemencia la construcción identitaria que asignan e identifican como imaginarios que han representado a lo largo de la historia; en la encuesta realizada de forma aleatoria a grupos heterogéneos de participantes sus edades evidenciaron que jóvenes como adultos definen posiciones iguales con respeto a las mujeres lesbianas, siendo una constante la reproducción de violencias simbólicas fundamentadas en el odio y la lesbofobia, generalizado para la población de mujeres lesbianas en la ciudad de Barranquilla.

La tarea más difícil es cambiar los esquemas mentales e ingresar otros generando en el individuo grandes dificultades de asimilación. No se pude olvidar que la dominación masculina afecta a las mujeres, de forma particular a las lesbianas, también particulariza las formas en que deben verse afectadas por los imaginarios, construcciones mentales que sustentan la formación de una deformación de la realidad de las mujeres lesbianas, que son diversas en sus apreciaciones de la identidad lésbica, son la consigna de años de invisibilización que ha denotado la injusticia más justificada desde la lógica de la opresión una patologización de una elección que constituye la justificación de las violencias en la población de lesbianas en Barranquilla.

\section{Recomendaciones}

1. Representación proactiva de mujeres lesbianas en los medios de comunicación, para trabajar las percepciones negativas a cerca de la población, visibilizando a las mujeres lesbianas como ciudadanas, asumiendo de este modo una campaña permanente. 
2. Liderazgo y participación de las mujeres en los grupos religiosos y representación en las instancias jurídicas, para que los asuntos de género sean de forma responsable apoyados, permitiendo, de este modo, que se capacite a los entes judiciales en prevención identificación de violencias contra mujeres lesbianas.

3. Trabajar la educación inclusiva en las escuelas, desarrollando desde la primera infancia conceptos de respeto y solidaridad; esta educación debe ser continuado hasta la universidad, lográndose de forma agresiva a través de la educación virtual.

4. Asignación de recursos para programas desde los entes de control, para trabajar los estereotipos como facilitador de violencias en los contextos de la familia y la escuela. Estos programas deben ser constantes e institucionalizarse como política de promoción de los derechos humanos.

5. Planes y programas que tengan como objetivo erradicar la lesbofobia; implementar campañas de capacitación para funcionarios de las áreas de la salud, derecho y policía para que las acciones estén encaminadas a 1 respeto y la seguridad de las lesbianas

6. Implementar programas de reconocimiento de derechos humano, aplicado a dueños de residencias, para que se les dé un trato digno, así como también haya vigilancia y seguimiento a casos de lesbofobia y violencias. 


\section{Referencias bibliográficas}

Araujo, K. (2000). El surgimiento de la violencia doméstica como problema público y objeto de políticas. Cepal, pp.133-145.

Careaga, G., y Cruz, S. (2004). Sexualidades diversas, aproximaciones para su análisis. México, D.F.: Maporrua.

Constitución Política de Colombia [Const.] (1991). 2da. Edición Legis.

Corporación Proyecto Colombia Diversa (2006) "Diversidad y Escuela: hacia una caracterización de las prácticas de inclusión y exclusión de la población LGBT en 5 jornadas de 4 escuelas distritales" Inclusión y Exclusión en la Escuela. Informe Final - 1 http://www.sdp.gov.co/ portal/page/portal/PortalSDP/SeguimientoPoliticas/politicasLGBTI/ Observatorio/Inclusion_Exclusion_en_Escuela_2006.pdf

Corte Constitucional, Sala Plena. (28 de enero de 2009) Sentencia C- 29 [MP Rodrigo Escobar Gil] Recuperado de: http://www.corteconstitucional.gov.co/relatoria/2009/c-029-09.htm

Falquet, J. (2004). Breves reseñas de teorías lésbicas. México: Fem-e-libros

Fernández, A. M. (1993). La mujer de la ilusión. Argentina: Paidós SAICF.

Foucault, M. (1977). Vigilar y castigar. Nacimiento de la prisión. México: Siglo XXI.

Gimeno, B. (2003). Una aproximación política al lesbianismo de construcción de la sexualidad. Servicios sociales y política social del consejo general de colegios oficiales de diplomados en trabajo social.

Human Rights Watch. (26 septiembre 2014). ONU: Resolución bistórica en defensa de los homosexuales. Recuperado de: https://www.hrw.org/ es/news/2014/09/26/onu-resolucion-historica-en-defensa-de-loshomosexuales

Instituto Nacional de Mujeres. (9 de Agosto de 2004). Interseccionalidad: una herramienta para la justicia de género y la justicia económica. Derechos de las mujeres y cambio económico, 9. Recuperado de: http://www.inmujeres. gub.uy/innovaportal/file/21639/1/2_awid_interseccionalidad.pdf 
Juliano, D. (27 de diciembre de 2005). Lesbianismo y roles de género. Rebelión. Recuperadode: http://www.rebelion.org/noticia.php?id=24700

López de Miguel, A. (24 de septiembre de 2014). Más de diez lesbianas son victimas de 'violaciones correctivas' en Sudáfrica cada semana. Público. Recuperado de: https://www.publico.es/internacional/mas-diez-lesbianas-son-victimas.html

Mira, A., Suárez, B., y Méndez, R. P. (2010). Centro de estudios Andaluces. Recuperado de: https://www.centrodeestudiosandaluces.es/datos/factoriaideas/PN06_10.pdf

Pisano, M. (1999). Incidencias lésbicas o el amor del propio reflejo. Santiago de Chile.

Platero, R. M. (2009). La construcción del sujeto lésbico. Les online, 1(1), 36-44.

Preciado, B. (2002). Manifiesto Contra-sexual. Madrid: Opera Prima.

Reinoso, B. G. (2005). Historia y análisis politico del lesbianismo la liberación de una generación. Barcelona: Gedisa.

Restrepo-Pimienta, J.; Molina-Imitola, E. (2014). Compresión Jurídicoprocesal de la seguridad social en la salud. Vis Iuris, 2(3), 163.

Rivera Tirado, C., (2013). Representaciones sociales de las mujeres lebianas en prensa escrita en Colombia. Tesis maestría. Bogotá.

Rodríguez, P. (1995) Las mujeres en la historia de Colombia. Bogotá: Norma

Scott, J. (1986). El género una categoría útil para el análisis histórico. México.

Recuperado de: http://www.inau.gub.uy/biblioteca/scott.pdf 